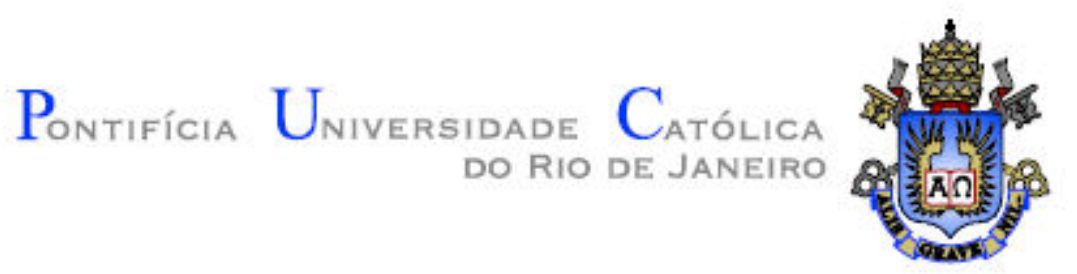

Paulo Daniel Salles Ramos

\title{
Regulação Dinâmica de Monopólios
}

\section{Dissertação de Mestrado}

\begin{abstract}
Dissertação apresentada como requisito parcial para obtenção do grau de Mestre pelo Programa de Pós-graduação em Economia do Departamento de Economia da PUC-Rio
\end{abstract}

Orientador: Prof. Vinícius Nascimento Carrasco 


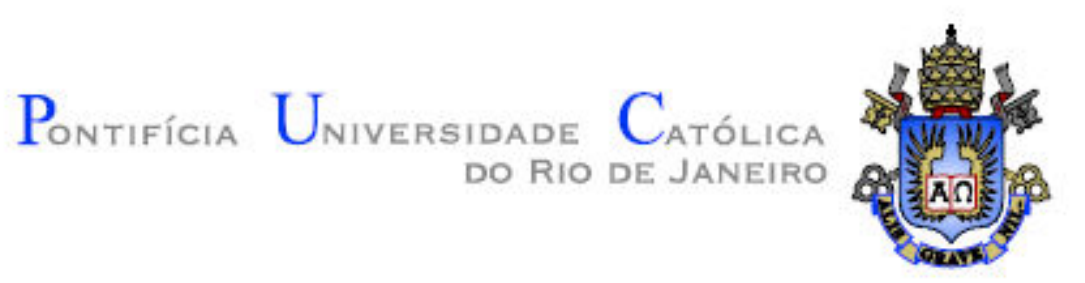

\section{Paulo Daniel Salles Ramos}

\section{Regulação Dinâmica de Monopólios}

Dissertação apresentada como requisito parcial para obtenção do grau de Mestre pelo Programa de Pós-graduação em Economia do Departamento de Economia do Centro de Ciências Sociais da PUC-Rio. Aprovada pela comissão examinadora abaixo assinada.

Prof. Vinícius Nascimento Carrasco

Orientador

PUC-Rio

Prof. Humberto Moreira

EPGE

Prof. Leonardo Rezende PUC-Rio

Prof. Mônica Herz Coordenadora do Centro de Ciências Sociais - PUC-Rio

Rio de Janeiro, 5 de Abril de 2011 
Todos os direitos reservados. É proibida a reprodução total ou parcial do trabalho sem autorização da universidade, do autor e do orientador.

\section{Paulo Daniel Salles Ramos}

Graduou-se em economia pela UnB em 2008. Cursou o mestrado em Economia pela PUC-Rio entre 2009 e 2010.

Ficha Catalográfica

Ramos,Paulo Daniel Salles

Regulação Dinâmica de Monopólios/Paulo Daniel Salles Ramos;orientador: Vinícius Nascimento Carrasco. I Rio de Janeiro : PUC-Rio, Departamento de Economia, 2011.

39 f: il. ; $29,7 \mathrm{~cm}$

1.Dissertação(Mestrado PontifíciaUniversidade Católica do Rio de Janeiro, Departamento de Economia.

Incluí referências bibliográficas.

1. Economia - Tese. 2. Regulação. 3. Desenho de Mecanismos. 4. Investimentos. I. Carrasco, Vinícius Nascimento. II.Pontifícia Universidade Católica do Rio de Janeiro. Departamento de Economia. III. Título.

CDD:330 


\section{Agradecimentos}

Aos meus pais, que sempre prezaram pela minha educação, às minhas irmãs pelo apoio e paciência na finalização da minha tese, aos parentes no Rio que me acolheram durante este tempo e ao meu orientador, que me conduziu pelo caminho. 


\section{Resumo}

Ramos, Paulo Daniel Salles; Carrasco, Vinícius Nascimento (Orientador). Regulação Dinâmica de Monopólios. PUC-Rio, 2011. 39p. Dissertação de Mestrado - Departamento de Economia, Pontifícia Universidade Católica do Rio de Janeiro.

O artigo estuda o problema de um regulador social que deseja induzir um monopolista natural a implementar um projeto de forma socialmente eficiente. O projeto tem longa duração e os custos do projeto variam de período a período de acordo com um processo estocástico. Adicionalmente, estuda-se a decisão de investimento do monopolista em tecnologia para se reduzir os custos deste projeto e como esta decisão está ligada ao contrato de produção oferecido pelo regulador. Mostra-se a forma que o contrato ótimo de regulação assume sob estas condições e como as distorções envolvidas no contrato são tão maiores quanto maiores forem as informações que a firma possui acerca de seus custos futuros. Mostra-se também que as distorções são tão maiores quanto maior for o investimento da firma em tecnologia e que por sua vez esse investimento caminha oposto aos custos sociais líquidos da tributação.

\section{Palavras-chave}

Regulação;Desenho de Mecanismos;Investimentos 


\begin{abstract}
Ramos, Paulo Daniel Salles; Carrasco, Vinícius Nascimento (Advisor).Dynamic Monopoly Regulation. PUC-Rio, 2011.39p. MSc.Dissertation - Departamento de Economia, Pontifícia Universidade Católica do Rio de Janeiro.
\end{abstract}

The paper studies the problem of a social regulator that wants to induce a natural monopolist to implement a project in a socially efficient way. The project has a long duration and project costs vary from period to period according to a stochastic process. Additionally, we study the investment decision of the monopolist in technology to reduce the cost of this project and how this decision is linked to the production contract offered by the regulator. We show the optimal contract that arises under these conditions and how the distortions involved in the contract are greater the higher the information that the firm has about its future costs. We also show that the distortions are greater the higher the firm's investment in technology and in turn that investment goes to the opposite net social cost of taxation.

\title{
Keywords
}

Regulation;Mechanism Design;Investiment 


\section{Sumário}

1 Introdução $\quad 9$

2 Desenvolvimento 13

2.1. Modelo 13

2.2. Contrato Ótimo com Informação Simétrica (benchmark) 15

2.3. Contrato Ótimo com informação assimétrica 17

2.4. Investimentos em tecnologia 32

$\begin{array}{ll}3 \text { Conclusão } & 37\end{array}$

4 Referências Bibliográficas $\quad 39$ 


\section{Lista de figuras}

Figura 1 Curvas de investimento para diferentes combinações de $\lambda$ e $\delta 38$ 